\title{
Ynol Ethers: Synthesis and Reactivity
}

\author{
Charlie Verrier, Sébastien Carret, and Jean-François Poisson*
}

\begin{abstract}
Ynol ethers are highly valuable substrates offering a wide range of reactivity. These highly electronrich heterosubstitued alkynes can be of great synthetic potential. In this mini-review, the different methods for the synthesis of ynol ethers are first presented, divided in three main approaches involving a $\beta$-elimination, a carbene rearrangement and a direct oxidation of an alkyne. Their reactivity is then summarized underlying their synthetic utility. This non-exhaustive review aims at presenting the intrinsic reactivity of these compounds, still underexploited in synthesis.
\end{abstract}

Keywords: Alkynes · Enol ethers · Ketenes · Synthesis · Ynol ethers

\section{Introduction}

Heterosubstituted alkynes are valuable synthetic intermediates showing a wide range of application. Among this class of derivatives, ynol ethers have continuously stimulated the creativity of synthetic chemists, leading to reliable synthetic accesses and to the emergence of a unique reactivity pattern. The presence of the oxygen directly connected to the sp-hybridized carbon results in a polarized, highly reactive, triple bond. Ynol ethers are known since 1908 when Slimmer reported the isolation and characterization of phenoxyacetylene. ${ }^{[1]}$ Nowadays, functionalized alkyl-, aryl-, and silyl ynol ethers are easily accessible and are used in a variety of synthetic transformations. In this short review, which is not an exhaustive report, the main synthetic pathways of ynol ethers and a summary of the reactivity profile are presented.

\section{Synthesis of Acetylenic Ethers}

Many strategies have been developed to synthesize acetylenic ethers, which can be divided into three different approaches: the ynols ethers can be obtained via a carbenoid rearrangement, by oxidation of alkynes or by $\beta$-elimination from enol ethers.

\section{Ynol Ethers by $\beta$-Elimination}

Historically, the elimination reaction was the first method to access acetylenic ethers, and probably remains the most efficient and versatile strategy. Slimmer in 1908 reported the synthesis of phenoxyacetylene from dibromoacetals and so-

\footnotetext{
${ }^{*}$ Correspondence: Prof. J.-F. Poisson

Université Grenoble Alpes

Département de Chimie Moléculaire (SERCO) UMR-5250 CNRS, IMCG FR-2607, 38041 Grenoble, France

E-mail: jean-francois.poisson@univ-grenoble-alpes.fr.
}

dium. Based on a similar strategy, Cramer reported a more convenient procedure using zinc instead of sodium, providing ethyl- or butylethynyl ethers (Scheme 1a). ${ }^{[2]}$ The bromination of bromoacetaldehyde dialkyl acetals followed by zinc-promoted $\beta$-elimination afforded 2-bromoenol ethers. A second base-promoted elimination provided the ynol ether. This double elimination procedure gives moderate yields, but is applicable to the preparation of terminal oxygenated alkynes. A similar method was later published by Newman, using chloroacetaldehyde diethyl acetal under Birch conditions (Scheme 1b). ${ }^{[3]}$ The intermediate sodium ethoxyacetylide could then react with different alkyl bromides, yielding substituted ynol ethers. A similar approach has been reported by the group of Nakai, ${ }^{[4]}$ using ethers of trifluoroethanol as precursors, and by Pericas using vinyl ethers. ${ }^{[5]}$

The enol ether $\beta$-substituted with a leaving group could also be generated from tribromoethanol. ${ }^{[6]}$ The bromo-silylenol ethers, obtained by bromine lithium exchange of the silyl ethers of tribromoethanol followed by a carbenoid rearrangement, were converted into the corresponding silyloxyacetylides using LDA (Scheme 1c). The intermediate lithium acetylide species could be trapped with various electrophiles.[6b]

Normant, using trichloroethylene, pioneered a complementary strategy, allowing the stepwise connection of the alkoxy moiety first, followed by the substituent at the second carbon. ${ }^{[7]}$ 1,2-Dichloroenol ethers are initially formed by reaction of alkoxides with in situ generated highly electrophilic dichloroacetylene. Deprotonation at low temperature followed by syn $\beta$-elimination, and a chlorine/lithium exchange leads to the formation of the lithio alkoxyacetylide (Scheme 2a). ${ }^{[8]}$ The latter can be hydrolyzed or trapped with a variety of electrophiles. This synthesis is certainly the most versatile method in term of scope

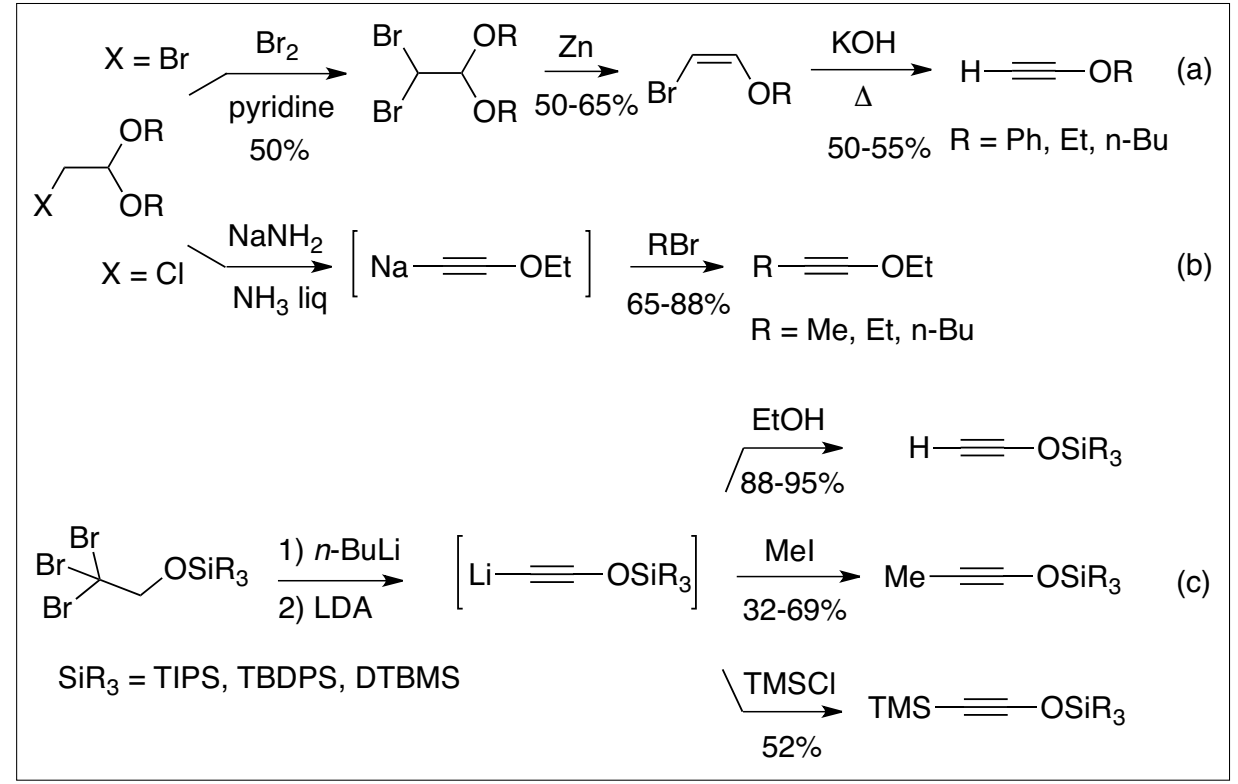

Scheme 1. Formation of ynol ethers through $\beta$-elimination. 
as both alkyl and aryl groups can be introduced on the oxygen atom, while many electrophiles are suitable for trapping the intermediate lithio acetylide.

Starting from ketones, or esters, acetylenic ethers can also be obtained. The formation of unstable enol triflates from $\alpha$-alkoxyketones, followed by a treatment with potassium tert-butoxide affords a variety of aryl- and alkyl-substituted ynol ethers (Scheme 2b). ${ }^{[9]}$ Similarly, acetic esters can be converted to ynol ethers through enol phosphonate intermediates (Scheme 2c). ${ }^{[10]}$

A final strategy was recently developed by Evano giving access to aryloxyalkynes in one step from dibromoalkenes (Scheme 2d). ${ }^{[11]}$ The sequence involves a coppercatalyzed $\mathrm{C}-\mathrm{O}$ cross coupling of phenol with gem dibromoalkenes to generate a bromo-enol ether that is in situ converted into the aryloxyalkyne with a base.

\section{Ynol Ethers via Carbene \\ Rearrangement}

The rearrangement of carbenes, or carbenoids, constitutes a valuable strategy to provide acetylenic ethers. Aromatic $\alpha$-silylated diazoketones undergo thermal silyl migration and carbene formation, which evolves through 1,2-migration to silyloxyalkynes. ${ }^{[12]}$ A carbenoid can also be formed from esters through the addition of dibromo-methyllithium. ${ }^{[13]}$ The carbenoid also evolves through 1,2-migration to lithio alkoxyacetylene (Scheme 3 ).

\section{Ynol Ethers from Alkynes}

Historically, the group of Stang was the first to use terminal alkynes as precursor for silyloxyalkynes. ${ }^{[14]}$ The reported twostep procedure relies on an oxidation of the alkyne by hypervalent iodine, producing an alkynyl tosylate. This intermediate can be detosylated with methyllithium, producing an ynolate that can be trapped with bulky silyl chlorides, yielding the corresponding silyloxyalkyne in moderated yield (Scheme 4a). Few years later, Julia reported a more straightforward route. ${ }^{[15]}$ The oxidation of a lithium acetylide by lithium tert-butylperoxide, followed by an $O$-silylation, provides a direct transformation of terminal alkynes to silyloxyalkynes (Scheme 4b). Finally, alkynyl-sulfonamides ${ }^{[16]}$ and alkynyl-sulfones ${ }^{[17]}$ treated by potassium tert-butoxide afford the corresponding tert-butoxyacetylenic ethers in good yields.

\section{Reactivity of Ynol Ethers}

\section{Nucleophilic Addition of Alkoxy Acetylide Anions}

The nucleophilic addition of the lithio alkoxyacetylides onto aldehydes and ketones was originally reported by Arens,

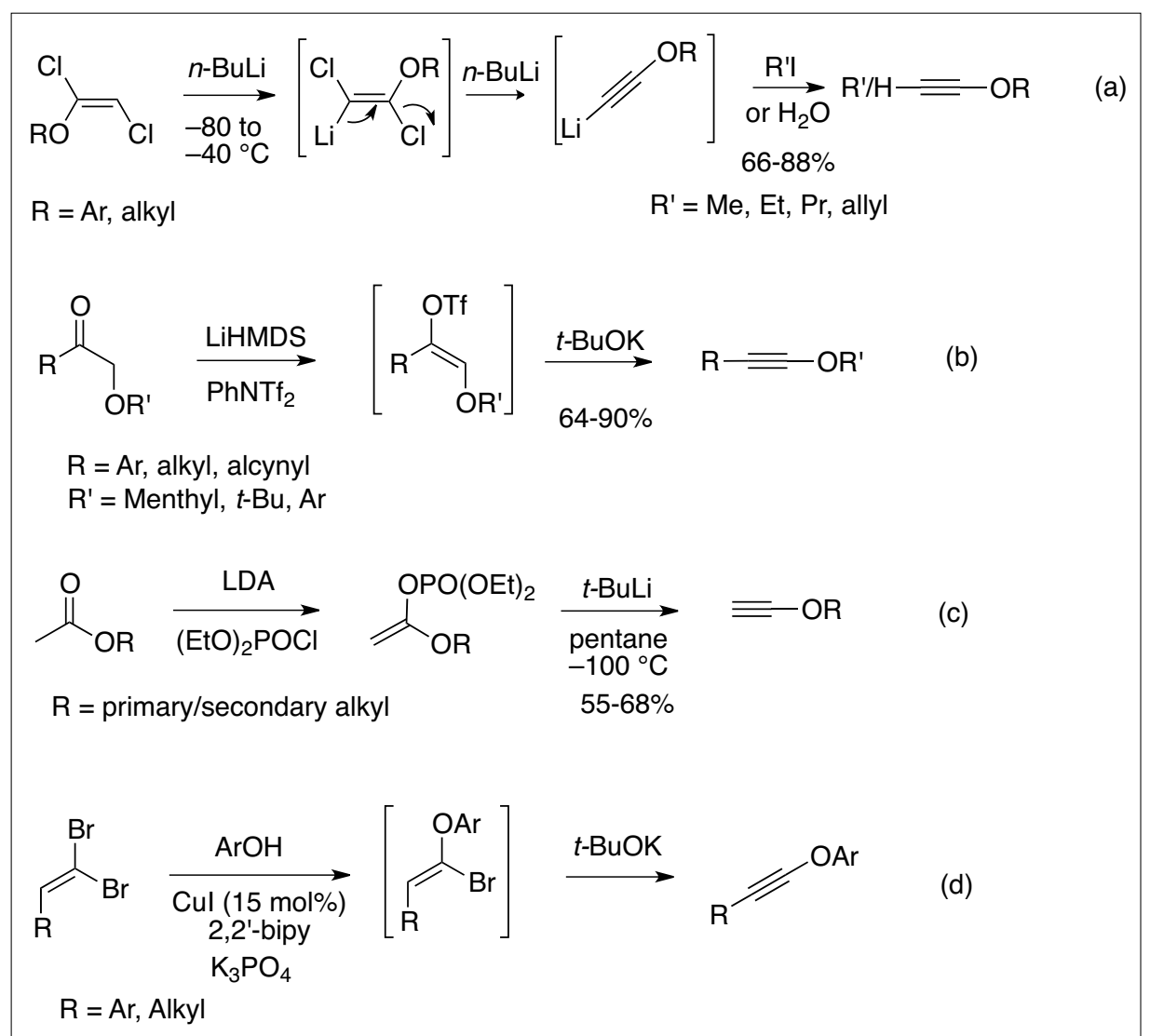

Scheme 2. Ynol ethers through $\beta$-elimination.

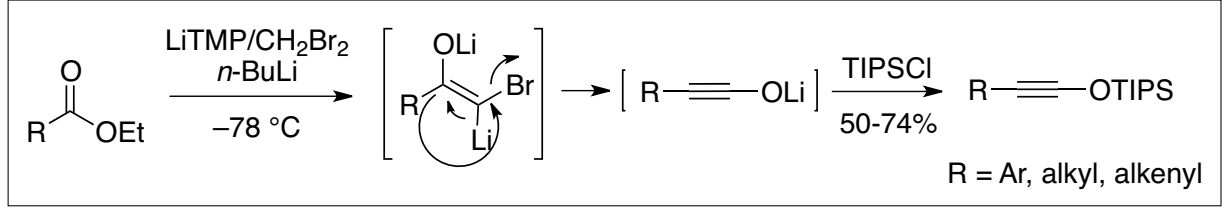

Scheme 3. Silyl ynol ethers by $\alpha$-elimination.

affording the corresponding propargylic alcohols. ${ }^{[18]}$ These propargylic alcohols showed an interesting reactivity; under acid- or metal-catalyzed activation the motif is converted into an $\alpha, \beta$-unsaturated ester, through the so-called Meyer-Schuster rearrangement (Scheme 5a). ${ }^{[19]}$ The overall transformation represents an interesting alternative to the classical olefination for hindered ketones. ${ }^{[20]}$ The addition of metallated ynol ethers to sulfonyl and sulfinyl imines provides a modular access to alkoxypropargyl amines. ${ }^{[21]}$ In the case of chiral sulfinylimines, the relative configuration of the propargylic center can be easily controlled and reversed depending

on the nature of the metal (Scheme 5b). [22] These additions of alkoxyacetylides offer an easy entry to functionalized acetylenic ethers, complementary to the direct oxidation of triple bonds in functionalized substrates, which in some cases may not be compatible with the oxidation conditions.

\section{Ynol Ethers as Ketene Precursors}

A first peculiar, and particularly interesting, reactivity of alkyl-ynol ethers is their propensity to rearrange into ketenes, via a retro-ene sigmatropy. This synthetically useful transformation, based on the thermal instability of acetylenic ethers,

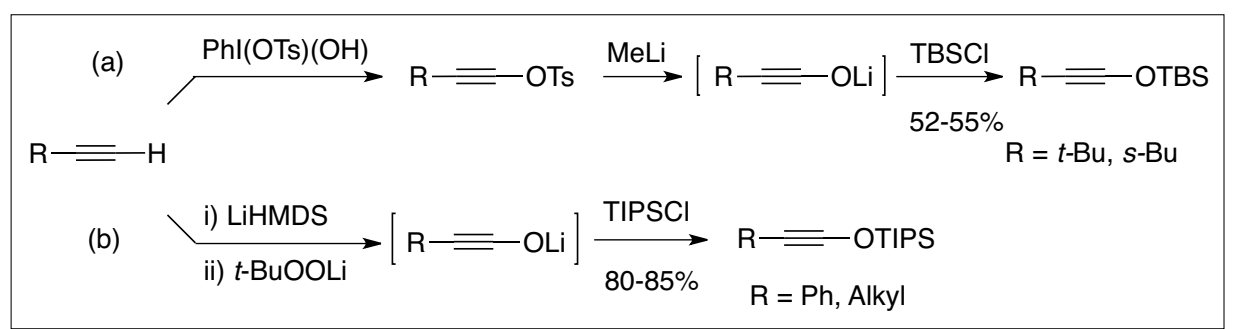

Scheme 4. Oxidation of terminal alkynes. 


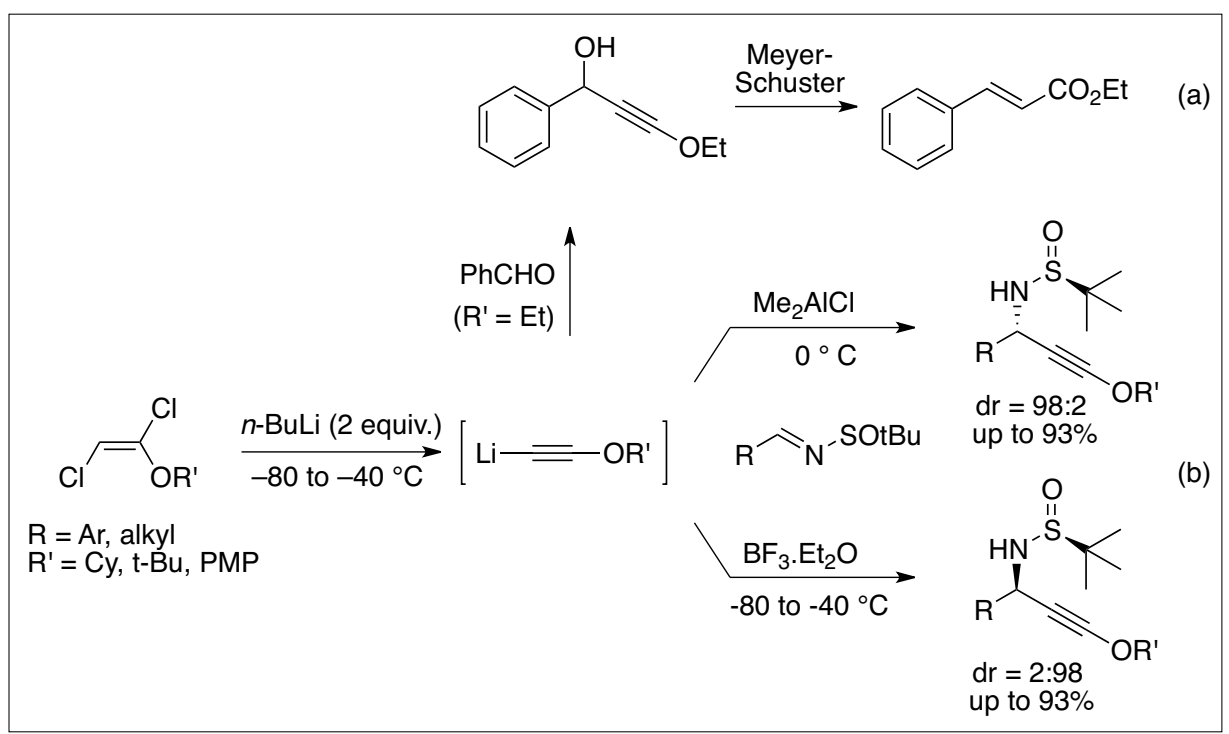

Scheme 5. Addition of metallated ynol ethers to aldehydes and imines.
The intermolecular carbolithiation of ynol ethers generates an unstable vinyllithium intermediate that spontaneously $\beta$-eliminates to produce the corresponding internal alkyne (Scheme 8a). ${ }^{[34]}$ Nevertheless, via an intramolecular cyclisation, the regioselectivity of the carbometallation can be reserved with an anti carbolithiation process, leading to a more stable organolithium species that can be trapped with various electrophiles (Scheme 8b). ${ }^{[35]}$

Normant and Alexakis reported the carbocupration of ynol ethers affording the vinyl ethers with a lack of selectivity when the triple bond was substituted. ${ }^{[36]}$ Recently, Marek published a solution to circumvent this lack of selectivity, with an effective regiodivergent carbocupration process, governed by the nature of the substituent on the oxygen of the acetylenic ethers (Scheme 8c). ${ }^{[37]}$ The carbometallation of ynol ethers very much depends on the oxygen substituent: primary alkyl ethers being more stable than secondary, the later being more stable than tertiary ether (Scheme 6a). ${ }^{[23]}$ It has also recently been shown that allylic and benzylic acetylenic ethers can rearrange at lower temperatures. ${ }^{[24]}$

This ketene generation is very useful for lactonization or macrolactonization, ${ }^{[25]}$ and has found an interesting application in the total synthesis of the complex natural product (+)-Acutiphycin (Scheme 6b).[26,27]

Taking advantage of this in situ ketene generation, intramolecular cycloadditions reactions have been developed. For instance, the [2+2] cycloaddition with an olefin offers fused four/five bicycles (Scheme 6c). [28]

Recently, Ready reported an elegant Sonogashira coupling of alkoxyacetylenes followed by a thermal sigmatropic rearrangement offering an in situ generation of a variety of aromatic ketenes. ${ }^{[29]}$ This ketene generation strategy offers an access to a wide range of carbonyl derivatives starting from a single ynol ether intermediate (Scheme 6d).

\section{Ynol Ethers as Precursors of Enol \\ Ethers}

Ynol ethers also afford a selective entry to $Z$ and $E$ enol ethers. Palladium-catalyzed hydrogenation selectively affords the $Z$ enol ether, ${ }^{[30]}$ whereas $\mathrm{LiAlH}_{4}$ reduction selectively leads to the $E$ enol ethers (Scheme 7). ${ }^{[31]}$ Ynol ethers are also exclusive precursors for a selective synthesis of disubstituted enol ethers. The hydroboration of ynol ethers produces exclusively an $E$ enol ether by syn addition of pinacolborane. ${ }^{[32]}$ Combined with a subsequent $\mathrm{Su}-$ zuki-Miyaura coupling, $\beta, \beta$-disubstituted vinyl ethers can be efficiently obtained in a one-pot procedure (Scheme 7). ${ }^{[33]}$

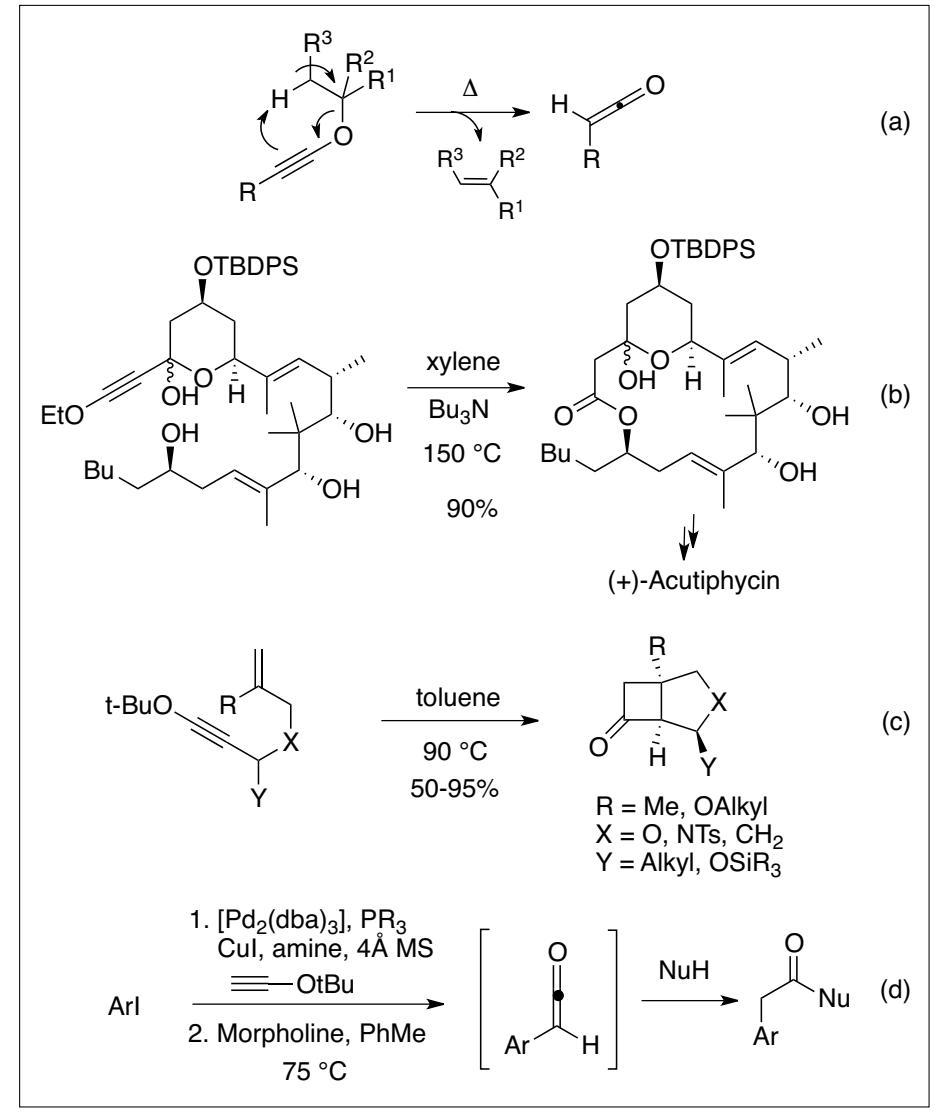

Scheme 6. Thermal formation of ketenes from ynol ethers.

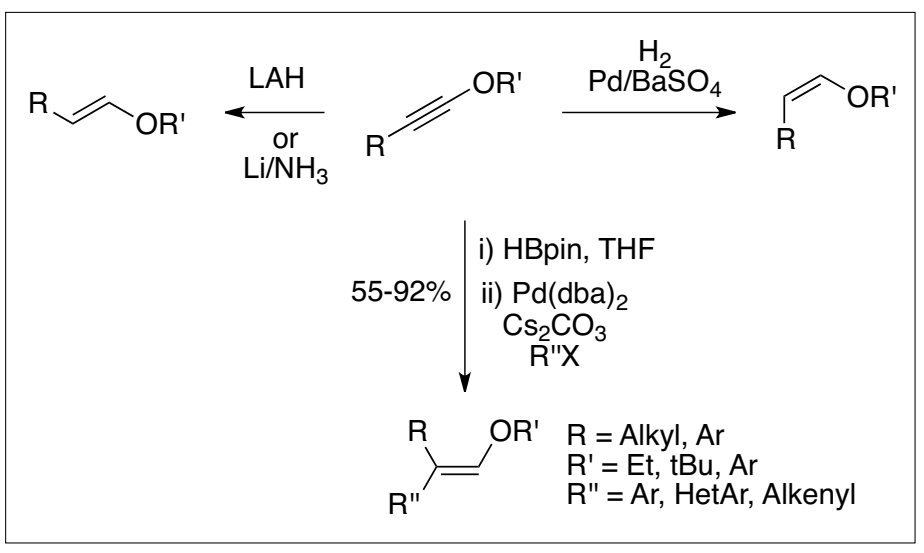

Scheme 7. Selective enol ether synthesis. 
has also recently been extended to carbonickelation ${ }^{[38]}$ and carbopalladation. ${ }^{[39]}$

\section{Cycloisomerization with Ynol Ethers}

Finally, acetylenic ethers can be engaged in cycloisomerization processes for the formation of carbocycles. Danheiser reported the [2+2] intermolecular cycloaddition between ketenes and ynol ethers, providing cyclobutanones that subsequently rearranges offering an entry to a variety of phenols. ${ }^{[40]}$ Using either triflic acid or gold complexes Kozmin reported the transformation of 1-silyloxy-1,5-enynes into cyclohexadienes. ${ }^{[41]}$ This gold-catalyzed ynol activation was then extended to the synthesis of more complex scaffolds involving a furan acting stepwise as nucleophile and electrophile (Scheme 9).[21]

\section{Conclusion}

Acetylenic ethers are valuable synthetic intermediates. The variety of reactivity of the polarized triple bond makes it a very useful synthon in organic synthesis: the panel of reactivity surely offers opportunities for further exploration, and for the discovery of novel transformations.

Received: July 29, 2015

[1] M. Slimmer, Chem. Ber. 1908, 36, 289.

[2] T. L. Jacobs, R. Cramer, J. E. Hanson, J. Am. Chem. Soc. 1942, 64, 223.

[3] M. S. Newman, J. R. Geib, W. M. Stalick, Org. Prep. Proced. Int. 1972, 4, 89.

[4] S. Shuichi, T. Nakai, K. Tanaka, N. Ishikawa, Tetrahedron Lett. 1978, 34, 3103.

[5] M. A. Pericas, F. Serratosa, E. Valenti, Tetrahedron 1987, 43, 2316.

[6] a) M. Pirrung, J. R. Hwu, Tetrahedron Lett. 1983, 24, 565; b) R. L. Danheiser, A. Nishida, S. Savariar, M. P. Trova, Tetrahedron Lett. 1988 , 29, 4917.

[7] J. Normant, Bull. Soc. Chim. Fr. 1963, 1876.

[8] B. Darses, A. Milet, C. Philouze, A. E. Greene, J.-F. Poisson, Org. Lett. 2008, 10, 4445.

[9] J. R. Sosa, A. A. Tudjarian, T. G. Minehan, Org. Lett. 2008, 10, 5091.

[10] J. A. Cabezas, A. C. Oehlschlager, J. Org. Chem. 1994, 59, 7523.

[11] K. Jouvin, A. Bayle, F. Legrand, G. Evano, Org. Lett. 2012, 14, 1652.

[12] G. Maas, R. Brückmann, J. Org. Chem. 1985, 50, 2802.

[13] a) C. J. Kowalski, G. S. Lal, M. J. Haque, J. Am. Chem. Soc. 1986, 108, 7127; b) C. J. Kowalski, R. E. Reddy, J. Org. Chem. 1992, 57, 7194.

[14] P. J. Stang, K. A. Roberts, J. Am. Chem. Soc. 1986, 108, 7125 .

[15] M. Julia, V. Pfeuty Saint-James, J.-N. Verpeaux, Synlett 1993, 3, 233.

[16] V. J. Gray, B. Slater, J. D. Wilden, Chem. Eur. J. 2012, 18, 15582

[17] L. Marzo, A. Parra, M. Frias, J. Alemen, J. L. G. Ruano, Eur. J. Org. Chem. 2013, 4405.

[18] J. C. W. Postma, J. F. Arens, Rec. Trav. Chim. Pays-Bas 1956, 75, 1408.

[19] A. E. Douglas, S. S. Lopez, G. B. Dudley, Tetrahedron 2008, 64, 6988.

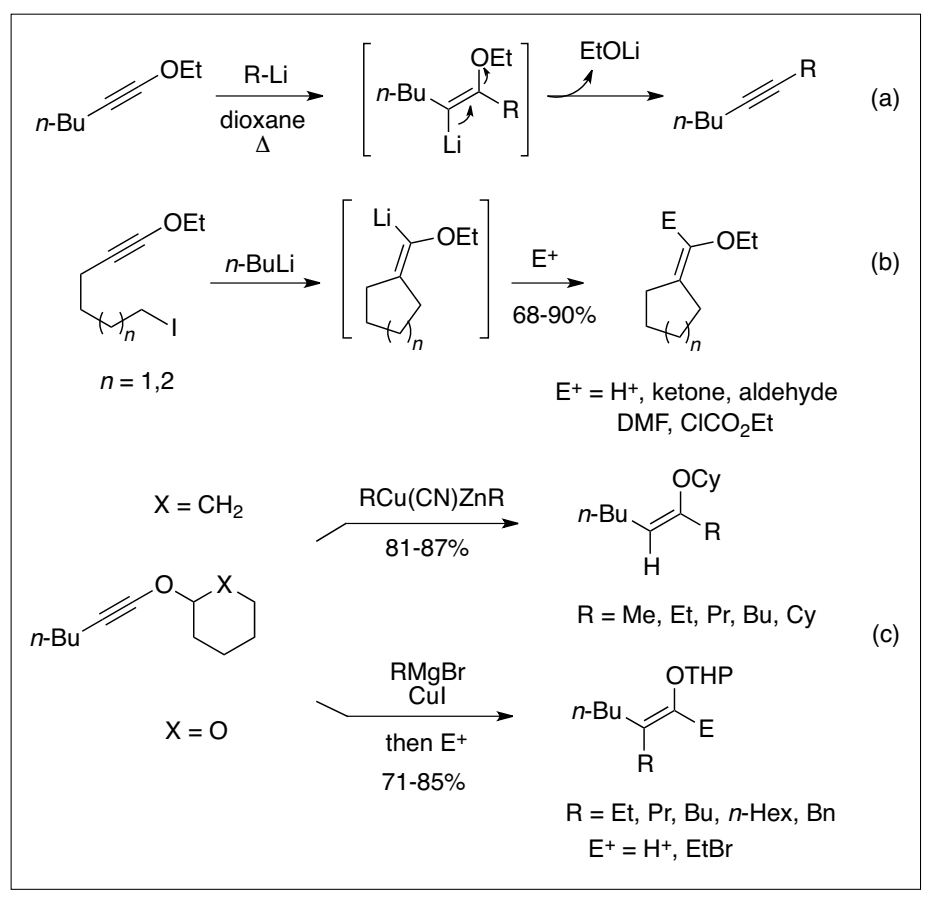

Scheme 8. Carbometallation of ynol ethers.

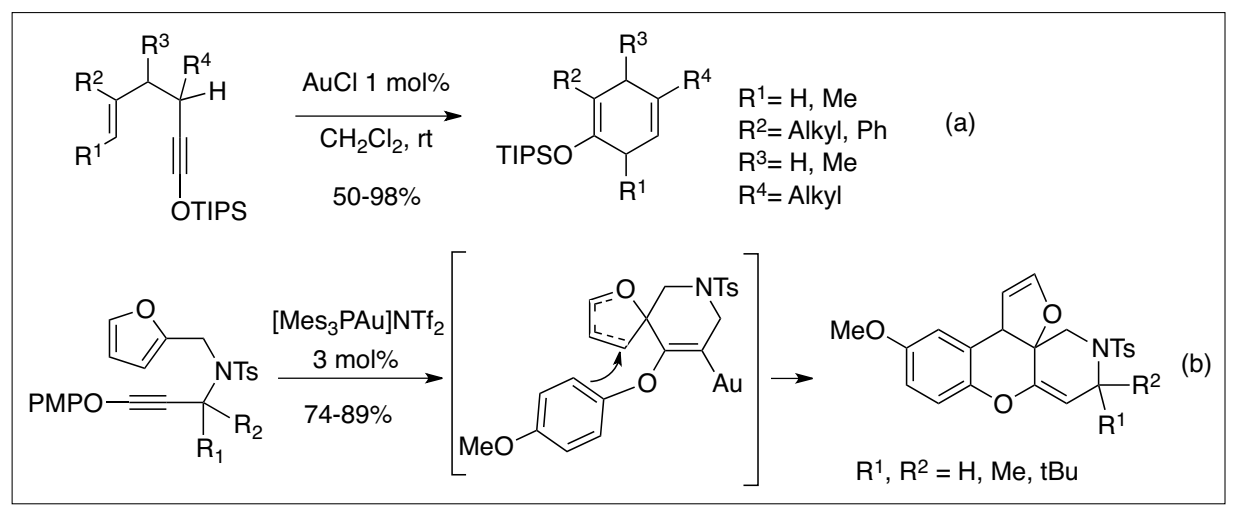

Scheme 9. Cycloisomerization involving ynol ethers.

[20] D.A.Engel, G.B.Dudley, Org. Lett. 2006, 8, 4027.

[21] S. K. Hashmi, M. Rudolph, J. Huck, W. Frey, J. Bats, M. Hamzic, Angew. Chem. Int. Ed. 2009, 48,5848 .

[22] a) C. Verrier, S. Carret, J.-F. Poisson, Org. Lett. 2012, 14, 5122; b) C. Verrier, S. Carret, J.-F. Poisson, Monatsh. Chem. 2013, 144, 455; c) C. Verrier, S. Carret, J.-F. Poisson, Org. Biomol. Chem. 2014, 12, 1875.

[23] J. J. Van Daalen, A. Kraak, J. F. Arens, Rec. Trav. Chim. Pays-bas 1961, 80, 810.

[24] a) J. R. Sosa, A. A. Tudjarian, T. G. Minehan, Org. Lett. 2008, 10, 5091; b) A. A. Tudjarian, T. G. Minehan, J. Org. Chem. 2011, 76, 3576.

[25] L. Liang, R. Ramaseshan, D. I. MaGee, Tetrahedron 1993, 49, 2159.

[26] R. M. Moslin, T. F. Jamison, J. Am. Chem. Soc. 2006, 128, 15106.

[27] For lactams and imides formation see: a) D. I. MaGee, M. Rameseshan, Synlett 1994, 743; b) D. I. MaGee, M. Rameseshan, J. Leach, Can. J. Chem. 1995, 73, 2111.

[28] V.Tran, T. G. Minehan, Org. Lett. 2011, 13, 6588.

[29] W. Zhang, J. M. Ready, Angew. Chem. Int. Ed. 2014, 53, 8980

[30] A. E. Douglas, S. S. Lopez, G. B. Dudley, Tetrahedron 2008, 64, 6988 .

[31] a) J. Ceccon, A. E. Greene, J. F. Poisson, Org. Lett. 2006, 8, 4739; b) B. Darses, A. E. Greene, S. C. Coote, J.-F. Poisson, Org. Lett. 2008, 10, 821 ; c) J. Ceccon, G. Danoun, A. E. Greene, J.F. Poisson, Org. Biomol. Chem. 2009, 7, 2029; d) G. Danoun, J. Ceccon, A. E. Greene, J.-F. Darses, A. E. Greene, J.-F. Poisson, Org. Lett. 2010, 12, 3994.

[32] R. W. Hoffmann, J. Krüger, D. Brückner, New. J. Chem. 2001, 25, 102.

[33] W. Cui, M. Mao, G. Zhu, J. Org. Chem. 2013, $78,9815$.

[34] J. G. A. Kooyan, H. P. G. Hendriks, P. P. Montijn, L. Brandsma, J. F. Arens, Rec. Trav. Chim. Pays-Bas 1968, 87, 69. K. E. Ellestad, J. B. Stallman, J. Am. Chem. Soc. 1993, 115, 7023; b) R. Hanna, B. Daoust, Tetrahedron 2011, 67, 92; c) R. Lhermet, M. Ahmad, C. Hauduc, C. Fressigne, M. Durandetti, J. Maddaluno, Chem. Eur. J. 2015, 21,8105 .

[36] A. Alexakis, G. Cahiez, J. F. Normant, J. Villieras, Bull. Soc. Chim. Fr. 1977, 693.

[37] a) L. Levin, A. Basheer, I. Marek, Synlett 2010, 329; b) A. Basheer, I. Marek, Beilstein J. Org. Chem. 2010, 6.

[38] N. Saito, Z. Sun, Y. Sato, Chem. Asian J. 2015, 10, 1170 .

[39] M. Hari Babu, V. Dwivedi, R. Kant, M. Sridhar Reddy, Angew. Chem. Int. Ed. 2015, 54, 3783.

[40] R. L. Danheiser, S. K. Gee, J. Org. Chem. 1984, 49, 1672.

[41] L. Zhang, S. A. Kozmin, J. Am. Chem. Soc. 2004, 126, 11806. For a recent review on silyloxyalkynes in annulation reactions, see: $\mathrm{H}$. Qian, W. Zhao, J. Sun, Chem. Rec. 2014, 14, 1070.
Poisson, Eur. J. Org. Chem. 2009, 4221; e) B.

[35] a) R. L. Funk, G. L. Bolton, K. M. Brummond, 